Check for updates

Cite this: RSC Adv., 2017, 7, 42570

Received 28th July 2017

Accepted 28th August 2017

DOI: 10.1039/c7ra08355f

rsc.li/rsc-advances

\title{
A phosphine-free, atom-efficient cross-coupling reaction of triorganoindiums with acyl chlorides catalyzed by immobilization of palladium(0) in MCM-41†
}

\begin{abstract}
Jiankang Miao, Bin Huang, Haiyi Liu and Mingzhong Cai (D) *
The first phosphine-free heterogeneous palladium(0)-catalyzed cross-coupling of triorganoindiums with acyl chlorides has been developed that proceeds smoothly in THF at $68{ }^{\circ} \mathrm{C}$ and provides a general and powerful tool for the synthesis of various valuable aryl ketones and $\alpha, \beta$-acetylenic ketones with high atom-economy and high yield. This phosphine-free heterogeneous palladium(0) catalyst can be easily prepared from commercially available reagents and recovered by a simple filtration of the reaction solution and used for at least 10 consecutive trials without any decreases in activity. Our system not only avoids the use of phosphine ligands, but also solves the basic problem of palladium catalyst recovery and reuse.
\end{abstract}

\section{Introduction}

Both aryl ketones ${ }^{1}$ and $\alpha, \beta$-acetylenic ketones ${ }^{2}$ are important building blocks for a large number of natural products and pharmaceutical compounds. The development of various approaches to these unsymmetrical ketones is of great interest and many methods for their preparation have been reported. One general and straightforward route to aryl ketones is the Friedel-Crafts acylation of aryl cycles with acid halides or acid anhydrides. ${ }^{3}$ However, this methodology suffers from some drawbacks such as the use of more than a stoichiometric amount of aluminum trichloride, which is incompatible with many functional groups, production of a large amount of highly toxic and corrosive waste, and narrow scope of substrates. Traditionally, $\alpha, \beta$-acetylenic ketones are usually prepared via the acylation of alkynylmetal reagents with acid chlorides ${ }^{4}$ or palladium-catalyzed coupling of acyl chlorides with terminal alkynes. ${ }^{5}$ Generally, the preparation of unsymmetrical ketones by transition-metal-catalyzed cross-coupling reaction is severely limited, since the organometallic partners often react with the product ketone.

The development of novel transition-metal-catalyzed crosscoupling reactions with high degrees of conversion of the organometallic species, high chemoselectivity, and the ability to form carbon-carbon bonds between all of the different carbon types ( $\mathrm{sp}^{3}, \mathrm{sp}^{2}$, and $\left.\mathrm{sp}\right)$ is still of considerable interest. Besides,

Key Laboratory of Functional Small Organic Molecules, Ministry of Education, College of Chemistry \& Chemical Engineering, Jiangxi Normal University, Nanchang 330022, P. R. China.E-mail: mzcai@jxnu.edu.cn

$\dagger$ Electronic supplementary information (ESI) available. See DOI: 10.1039/c7ra08355f the minimization of byproduct formation ${ }^{6}$ and the choice of chemical processes with little or no risk associated to humans or the environment are major contemporary concerns in the chemistry community. ${ }^{7}$ Some organometallic reagents used in cross-coupling reactions have shown limitations concerning the use of alkyl $\left(\mathrm{sp}^{3}\right)$ organometallics as coupling partners, the toxicity associated with the metal, and undesirable side reactions. During the past two decades, the applications of indium in organic synthesis have increased steadily due to the apparent low toxicity ${ }^{8}$ associated with indium as well as other interesting chemical properties, such as low nucleophilicity and heterophilicity or similarities with magnesium, zinc, and tin. ${ }^{9}$ Triorganoindium compounds $\left(\mathrm{R}_{3} \mathrm{In}, \mathrm{R}=\right.$ alkyl, alkenyl, alkynyl, aryl) are increasingly gaining attention as efficient coupling partners for transition-metal-catalyzed cross-couplings with a variety of organic electrophiles such as aryl (or alkenyl) halides (or pseudohalides) and acid chlorides ${ }^{10}$ and the carbonylative cross-couplings ${ }^{11}$ because of their high efficiency, versatility, atom-economy, and chemoselectivity. However, in most cases, homogeneous palladium complexes such as $\operatorname{Pd}\left(\mathrm{PPh}_{3}\right)_{4}$, $\mathrm{PdCl}_{2}\left(\mathrm{PPh}_{3}\right)_{2}$, and $\mathrm{Pd}(\mathrm{dppf}) \mathrm{Cl}_{2}$ are usually used as catalysts for these cross-coupling reactions. The problem with homogeneous catalysis is the difficulty to separate the expensive palladium catalyst from the reaction mixture and the impossibility to reuse it in consecutive reactions. In addition, homogeneous catalysis might result in unacceptable heavy metal contamination of the desired isolated product due to the leaching of the metal. These problems may have a very serious negative impact on their possible industrial applications, especially the pharmaceutical industry. In contrast, heterogeneous catalysts can be easily separated from the reaction mixture by a simple filtration of the 


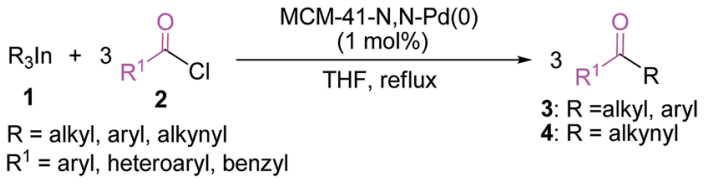

Scheme 1 Synthesis of aryl ketones and $\alpha, \beta$-acetylenic ketones via heterogeneous $\mathrm{Pd}(0)$-catalyzed cross-coupling of triorganoindiums with acid chlorides.

reaction solution and reused in successive reactions provided that the active sites have not become deactivated. Heterogeneous catalysis also helps to reduce wastes derived from reaction workup, contributing to the development of green and sustainable chemical processes. ${ }^{12}$ From the viewpoints of economical and environmental concern, the development of immobilized transition-metal catalysts is challenging and important. So far, supported palladium catalysts have successfully been used in many carbon-carbon and carbon-heteroatom bond formation reactions, ${ }^{13}$ however, to the best of our knowledge, no example of a heterogeneous palladium-catalyzed cross-coupling reaction of triorganoindiums with organic electrophiles has been described until now.

The discovery of mesoporous MCM-41 materials has provided a new possible candidate for an ideal solid support to immobilize homogeneous catalysts and given an enormous stimulus to research in heterogeneous metal catalysis. ${ }^{\mathbf{1 4}}$ The hexagonally-ordered MCM-41 material possesses large and uniform pore size, ultrahigh surface area, big pore volume and rich silanol groups in the inner walls. ${ }^{15}$ To date, some functionalized MCM-41-supported palladium, ${ }^{16}$ rhodium, ${ }^{17}$ molybdenum, ${ }^{18}$ gold $^{19}$ and copper ${ }^{20}$ complexes have been successfully used as potentially green and sustainable catalysts in organic reactions. Recently, we have reported the first preparation of an MCM-41-immobilized palladium(II)-Schiff base complex [MCM$\left.41-N, N-\mathrm{Pd}(\mathrm{OAc})_{2}\right]$ and its successful application to the atomefficient cross-coupling of triarylbismuths with aryl iodides. ${ }^{21}$ In continuing our efforts to develop greener synthetic pathways for organic transformations, ${ }^{\mathbf{1 6 d - f , 1 9 d , 2 0}}$ herein we wish to report the first phosphine-free heterogeneous palladium(0)-catalyzed cross-coupling reaction of triorganoindiums with acid chlorides by using an MCM-41-immobilized palladium(0)-Schiff base complex [MCM-41-N,N-Pd(0)] as a recyclable catalyst. The reactions proceeded in THF smoothly under mild conditions, yielding a variety of aryl ketones and $\alpha, \beta$-acetylenic ketones in good to excellent yields with high atom-economy and recyclability of the catalyst (Scheme 1).

\section{Results and discussion}

Although phosphine ligands can stabilize palladium and influence its catalytic activity, undoubtedly, the simplest and cheapest palladium catalysts are still the phosphine-free systems. Furthermore, the procedure for the synthesis of immobilized phosphine palladium complexes is rather complicated since the preparation of the heterogeneous phosphine ligands requires multi-step sequences. Therefore, the development of phosphine-free supported palladium complex catalysts having a high activity and good stability is a topic of enormous importance. The MCM-41-immobilized palladiu$\mathrm{m}(\mathrm{II})-\mathrm{Schiff}$ base complex [MCM-41- $N, N-\mathrm{Pd}(\mathrm{OAc})_{2}$ ] could easily be prepared starting from mesoporous material MCM-41 and commercially available 3-aminopropyltriethoxysilane, pyridine2-carboxaldehyde, and $\mathrm{Pd}(\mathrm{OAc})_{2}$ as shown in Scheme 2 according to our previous procedure. ${ }^{21}$ Firstly, the mesoporous MCM-41 was condensed with 3-aminopropyltriethoxysilane in toluene at $100{ }^{\circ} \mathrm{C}$ for $24 \mathrm{~h}$, followed by the silylation with $\mathrm{Me}_{3}$ $\mathrm{SiCl}$ in toluene at room temperature for $24 \mathrm{~h}$ to give 3aminopropyl-functionalized MCM-41 material (MCM-41- $\mathrm{NH}_{2}$ ). The latter was subsequently treated with pyridine-2carboxaldehyde in dry EtOH at $80{ }^{\circ} \mathrm{C}$ for $12 \mathrm{~h}$ to afford the Schiff base-functionalized MCM-41 (MCM-41- $N, N$ ), which was then reacted with $\mathrm{Pd}(\mathrm{OAc})_{2}$ in acetone under reflux for $72 \mathrm{~h}$ to generate the MCM-41-immobilized palladium(II)-Schiff base complex [MCM-41- $N, N-\mathrm{Pd}(\mathrm{OAc})_{2}$ ] as a light yellow powder. Finally, the treatment of MCM-41-N,N-Pd(OAc) $)_{2}$ with hydrazine hydrate in EtOH at $30{ }^{\circ} \mathrm{C}$ for $3 \mathrm{~h}$ afforded the MCM-41immobilized palladium(0)-Schiff base complex [MCM-41- $N, N$ $\operatorname{Pd}(0)]$ as a gray powder.

Elemental analyses and X-ray photoelectron spectroscopy (XPS) were used to characterize the MCM-41-immobilized palladium(0)-Schiff base complex. The $\mathrm{N}: \mathrm{Pd}$ mole ratio of the MCM-41- $N, N-\mathrm{Pd}(\mathrm{OAc})_{2}$ was determined to be 5.2. The XPS data for MCM-41- $N, N-\mathrm{Pd}(0)$ (fresh), MCM-41- $N, N-\mathrm{Pd}(\mathrm{OAc})_{2}$, $\mathrm{MCM}-41-N, N, \operatorname{Pd}(\mathrm{OAc})_{2}$, metal $\mathrm{Pd}$, and $\mathrm{MCM}-41-N, N-\mathrm{Pd}(0)$ (used) are listed in Table 1 . It can be seen that the binding energies of $\mathrm{Si}_{2 \mathrm{p}}$ and $\mathrm{O}_{1 \mathrm{~s}}$ of MCM-41-N,N-Pd(OAc)$)_{2}$ were similar to those of MCM-41-N,N. However the difference of $\mathrm{N}_{1 \mathrm{~s}}$ binding energies between MCM-41- $N, N-\mathrm{Pd}(\mathrm{OAc})_{2}$ and MCM-41- $N, N$ was $1.1 \mathrm{eV}$. The binding energy of $\mathrm{Pd}_{3 \mathrm{~d} 5 / 2}$ in $\mathrm{MCM}-41-N, N-\mathrm{Pd}(\mathrm{OAc})_{2}$ was $0.9 \mathrm{eV}$ less than that in $\mathrm{Pd}(\mathrm{OAc})_{2}$, but $1.9 \mathrm{eV}$ larger than that in metal Pd. These results showed that a coordination bond between $\mathrm{N}$ and Pd was formed in MCM-41-N,N-Pd(OAc $)_{2}$ and the oxidation state of palladium in $\mathrm{MCM}-41-N, N-\mathrm{Pd}(\mathrm{OAc})_{2}$ was $\mathrm{Pd}(\mathrm{II}) .{ }^{22}$ The binding energy $\left(336.2 \mathrm{eV}\right.$ ) of $\mathrm{Pd}_{3 \mathrm{~d} 5 / 2}$ of the freshly prepared MCM-41- $N, N-\operatorname{Pd}(0)$ was lower than the binding energy $(337.4 \mathrm{eV})$ of $\mathrm{Pd}_{3 \mathrm{~d} 5 / 2}$ of $\mathrm{MCM}-41-N, N-\mathrm{Pd}(\mathrm{OAc})_{2}$. The $\mathrm{Pd}_{3 \mathrm{~d} 5 / 2}$ binding energy depends strongly on the nature of the ligands. Consequently, it is impossible to identify the reduced complex as a zerovalent one on the basis of its $\mathrm{Pd}_{3 \mathrm{~d} 5 / 2}$ binding energy only. However, the shift (lower) of $\mathrm{Pd}_{3 \mathrm{~d} 5 / 2}$ binding energy together with the change in color from light yellow to gray suggests that the reduction of the starting palladium(II) complex to the zerovalent state has taken place. The binding energy of $\mathrm{Pd}_{3 \mathrm{~d} 5 / 2}$ of the used MCM-41- $N, N-\operatorname{Pd}(0)$ catalyst was determined to be $336.3 \mathrm{eV}$, which indicating that the oxidation state of palladium in used MCM-41-N,N-Pd(0) catalyst after reaction was still $\operatorname{Pd}(0)$.

The MCM-41-immobilized palladium(0)-Schiff base complex $[\mathrm{MCM}-41-N, N-\mathrm{Pd}(0)]$ was then used as the catalyst for the crosscoupling reaction of triorganoindiums with acid chlorides. In our initial screening experiments, the cross-coupling of benzoyl chloride with $\mathrm{Ph}_{3} \mathrm{In}$ (0.37 equiv.) in THF was chosen as the model reaction to optimize the reaction conditions and the 

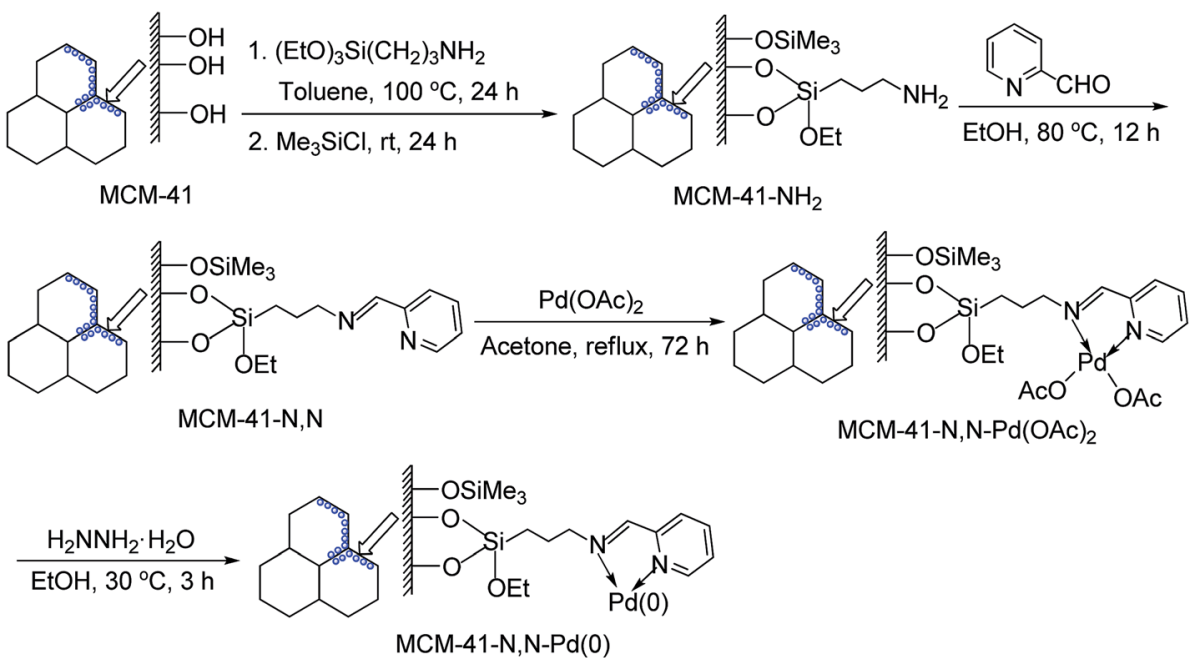

Scheme 2 Preparation of MCM-41-N,N-Pd(0) complex.

Table 1 XPS data for MCM-41-N,N-Pd(0) (fresh), MCM-41-N,N$\mathrm{Pd}(\mathrm{OAC})_{2}, \mathrm{MCM}-41-N, N, \mathrm{Pd}(\mathrm{OAC})_{2}$, metal Pd, and MCM-41-N,N-Pd(0) (used) ${ }^{a}$

\begin{tabular}{lcccc}
\hline Sample & $\mathrm{Pd}_{3 \mathrm{~d} 5 / 2}$ & $\mathrm{~N}_{1 \mathrm{~s}}$ & $\mathrm{Si}_{2 \mathrm{p}}$ & $\mathrm{O}_{1 \mathrm{~s}}$ \\
\hline MCM-41- $N, N-\mathrm{Pd}(0)$ (fresh) & 336.2 & 400.9 & 103.3 & 533.2 \\
MCM-41-,$N$-Pd(OAc) & 337.4 & 400.8 & 103.4 & 533.2 \\
MCM-41- $N, N$ & & 399.7 & 103.3 & 533.1 \\
Pd(OAc) & 338.3 & & & \\
Metal Pd & 335.5 & & & \\
MCM-41- $N, N-P d(0)$ (used) & 336.3 & 400.7 & 103.4 & 533.3
\end{tabular}

${ }^{a}$ The binding energies are referenced to $\mathrm{C}_{1 \mathrm{~s}}(284.6 \mathrm{eV})$ and the energy differences were determined with an accuracy of $\pm 0.2 \mathrm{eV}$.

results are summarized in Table 2 . First, the effect of various supported palladium complexes on the model reaction was examined in THF at $68{ }^{\circ} \mathrm{C}$ (Table 2, entries 1-3). When the
MCM-41-immobilized palladium(II)-Schiff base complex [MCM$\left.41-N, N-\mathrm{Pd}(\mathrm{OAc})_{2}\right]$ was used as catalyst, benzophenone 3a was isolated in $71 \%$ yield (entry 1). To our delight, the yield of $\mathbf{3 a}$ could be improved to $88 \%$ by replacing the MCM-41- $N, N$ $\mathrm{Pd}(\mathrm{OAc})_{2}$ complex with the MCM-41-immobilized palladium(0)Schiff base complex [MCM-41-N,N-Pd(0)] (entry 2). We also tested the catalytic activity of the MCM-41-supported thioether palladium(0) complex [MCM-41-S-Pd(0)], ${ }^{23}$ which is an efficient and phosphine-free heterogeneous palladium catalyst for Suzuki coupling reaction reported by our group, but a lower yield of 3a was obtained (entry 3), so the MCM-41-N,N-Pd(0) complex was finally selected as the catalyst for the reaction. The result means that all three of phenyl groups attached to the indium were transferred to benzoyl chloride in the heterogeneous coupling reaction. Control experiments showed that palladium catalyst is essential for this ketone formation

Table 2 Reaction condition screening for the coupling reaction of $\mathrm{Ph}_{3} \ln \left(0.37\right.$ equiv.) with benzoyl chloride ${ }^{a}$

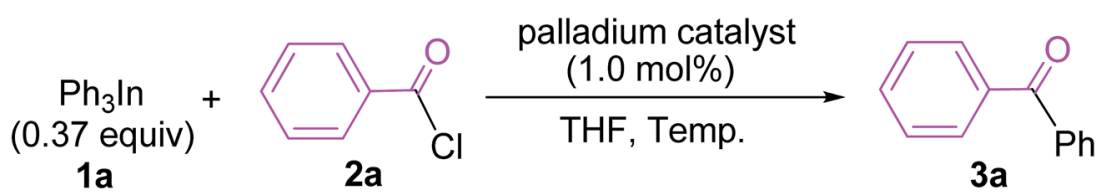

\begin{tabular}{|c|c|c|c|c|}
\hline Entry & Palladium catalyst & Temp. $\left({ }^{\circ} \mathrm{C}\right)$ & Time (h) & Isolated yield (\%) \\
\hline 1 & MCM-41-N,N-Pd(II) & 68 & 2 & 71 \\
\hline 2 & MCM-41-N,N-Pd(0) & 68 & 2 & 88 \\
\hline 4 & - & 68 & 12 & 0 \\
\hline 5 & $\mathrm{Pd}\left(\mathrm{PPh}_{3}\right)_{4}$ & 68 & 2 & 89 \\
\hline 6 & MCM-41- $N, N-\operatorname{Pd}(0)$ & 25 & 12 & 0 \\
\hline $9^{c}$ & MCM-41- $N, N-\operatorname{Pd}(0)$ & 68 & 1 & 89 \\
\hline
\end{tabular}

${ }^{a}$ All reactions were performed using $1.0 \mathrm{mmol}$ of benzoyl chloride, $0.37 \mathrm{mmol}$ of $\mathrm{Ph}_{3} \mathrm{In}, 1 \mathrm{~mol} \%$ of palladium catalyst in $5.0 \mathrm{~mL}$ of THF under Ar.

${ }^{b} 0.5 \mathrm{~mol} \%$ of MCM- $41-N, N-\operatorname{Pd}(0)$ was used. ${ }^{c} 2$ mol\% of MCM- $41-N, N-\operatorname{Pd}(0)$ was used. 
reaction (entry 4). When $\mathrm{Pd}\left(\mathrm{PPh}_{3}\right)_{4}$ was used as the catalyst, ${ }^{10 a}$ the desired product 3a was also isolated in $89 \%$ yield (entry 5), which indicating that catalytic activity of the phosphine-free heterogeneous palladium $(0)$ complex [MCM- $41-N, N-\operatorname{Pd}(0)]$ was comparable to that of $\mathrm{Pd}\left(\mathrm{PPh}_{3}\right)_{4}$. The heterogeneous crosscoupling reaction did not occur at $25{ }^{\circ} \mathrm{C}$ (entry 6). Lowering the reaction temperature to $50{ }^{\circ} \mathrm{C}$ resulted in a decreased yield (entry 7). Finally, the amount of the immobilized palladium catalyst was screened, and $1 \mathrm{~mol} \%$ loading of palladium was found to be optimal, a lower yield was observed and a longer reaction time was required when the amount of the catalyst was decreased to $0.5 \mathrm{~mol} \%$ (entry 8). Increasing the amount of the palladium catalyst could shorten the reaction time, but did not improve the yield of 3a obviously (entry 9). Therefore, the optimal catalytic system involved the use of MCM-41-N,N-Pd(0) (1 mol\%) in THF at $68{ }^{\circ} \mathrm{C}$ under Ar for $2 \mathrm{~h}$ (Table 2, entry 2).

With the optimal reaction conditions established, we tried to investigate the scope and limitations of this heterogeneous palladium(0)-catalyzed cross-coupling reaction of triorganoindiums with acid chlorides and the results are summarized in Table 3. As shown in Table 3, the coupling reactions of $\mathrm{Ph}_{3}$ In (1a) with a variety of aromatic acyl chlorides bearing either electron-donating or electron-withdrawing groups proceeded smoothly under the optimized conditions, generating the corresponding substituted benzophenones $\mathbf{3 b}-\mathbf{3 f}$ in excellent yields. The results indicated that the electronic properties of the substituents on benzene ring have limited influence on this heterogeneous palladium-catalyzed cross-coupling reaction. Reactions of sterically hindered 2-methylbenzoyl chloride and 2-methoxybenzoyl chloride also proceeded effectively to produce the desired 2-methylbenzophenone $\mathbf{3 g}$ and 2-methoxybenzophenone $3 \mathbf{h}$ in $83 \%$ and $86 \%$ yield, respectively. Bulky 1naphthoyl chloride and 2-naphthoyl chloride could afford the expected products $3 \mathbf{i}$ and $\mathbf{3} \mathbf{j}$ in high yields. It is noteworthy that the reactions of heteroaroyl chlorides such as thiophene-2carbonyl chloride and pyridine-3-carbonyl chloride with $\mathrm{Ph}_{3} \mathrm{In}$ also gave the desired phenyl heteroaryl ketones $\mathbf{3 k}$ and $\mathbf{3 1}$ in $90 \%$ and $84 \%$ yield, respectively. In addition to aroyl chlorides, phenylacetyl chloride proved to be also suitable coupling partner and could afford the expected 1,2-diphenylethanone 3m in $89 \%$ yield. However, other aliphatic acyl chlorides such as butyryl chloride and hexanoyl chloride were not reactive under

Table 3 Synthesis of aryl ketones via heterogeneous palladium(0)-catalyzed cross-coupling of acid chlorides with $\mathrm{Ph}_{3} \mathrm{In}$ and trialkylindiums ${ }^{a, b}$

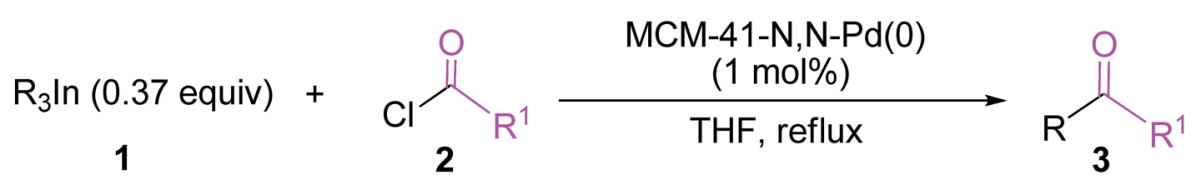

1a: $\mathrm{R}=\mathrm{Ph} ; 1 \mathrm{~b}: \mathrm{R}=\mathrm{Me} ; 1 \mathrm{c}: \mathrm{R}=n-\mathrm{Bu}$

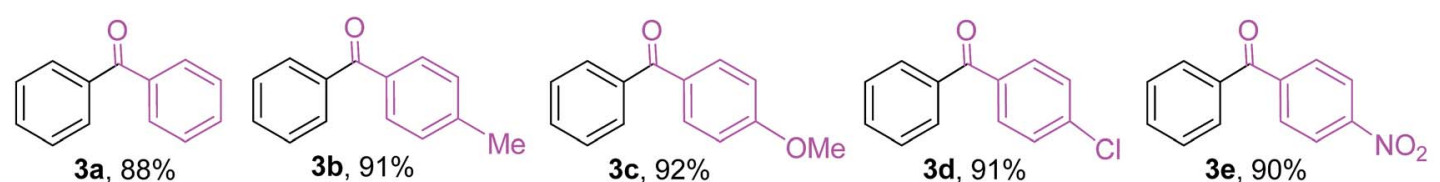<smiles>Cc1ccccc1C(=O)c1ccccc1</smiles><smiles>COc1ccccc1C(=O)c1ccccc1</smiles>

$3 \mathrm{~h}, 86 \%$<smiles>O=C(c1ccccc1)c1cccc2ccccc12</smiles>

3i, $88 \%$<smiles>O=C(c1ccccc1)c1ccc2ccccc2c1</smiles>

3j, $85 \%$<smiles></smiles><smiles>O=C(CF)c1ccccc1</smiles>
$3 \mathrm{~m}, 89 \%$<smiles>CC(=O)c1ccc(C(C)=O)cc1</smiles>
3n, $95 \%$<smiles>COc1ccc(C(C)=O)cc1</smiles>

3o, $93 \%$<smiles>CC(=O)c1ccc(Cl)cc1</smiles>

3p, $94 \%$<smiles>CC(=O)c1ccc(F)cc1</smiles>

3q, $90 \%$

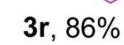<smiles>CC(=O)c1cccc2ccccc12</smiles>

3s, $91 \%$<smiles>CC(=O)c1cccs1</smiles>

3t, $92 \%$<smiles>CCCCC(=O)c1cccc(C)c1</smiles>

3 u, $90 \%$<smiles>CCCCC(=O)c1ccc(OC)cc1</smiles>

$3 v, 88 \%$<smiles>CCCC(=O)c1ccc(Cl)cc1</smiles>

3w, 93\%<smiles>CCCCC(=O)c1ccc(C#N)cc1</smiles>

$3 x, 91 \%$<smiles>CCCCC(=O)c1cccc2ccccc12</smiles>

3y, $90 \%$<smiles>CCCCC(=O)c1cccs1</smiles>

3z, $89 \%$

${ }^{a}$ All reactions were performed using $1.0 \mathrm{mmol}$ of acid chloride, $0.37 \mathrm{mmol}$ of $\mathrm{R}_{3} \mathrm{In}, 1 \mathrm{~mol} \%$ of MCM-41-N,N-Pd(0) in $5.0 \mathrm{~mL}$ of THF at $68{ }^{\circ} \mathrm{C}$ under $\mathrm{Ar}$ for 2 h. ${ }^{b}$ Isolated yield based on acid chloride used. 


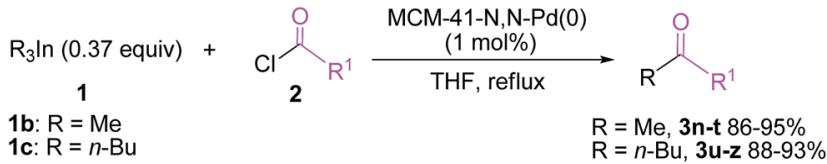

Scheme 3 Heterogeneous $\mathrm{Pd}(0)$-catalyzed cross-coupling of $\mathrm{Me}_{3} \mathrm{In}$ and $n-\mathrm{Bu}_{3} \mathrm{In}$ with acid chlorides.

the conditions optimized for aromatic acyl chlorides and no desired cross-coupling products were detected. The similar observation was made by our group in heterogeneous palladiumcatalyzed cross-coupling of acyl chlorides with triarylbismuths. ${ }^{24}$ Under the reaction conditions optimized for $\mathrm{Ph}_{3} \mathrm{In}(\mathbf{1 a}), \mathrm{Me}_{3} \mathrm{In}$ (1b) and $n-\mathrm{Bu}_{3} \mathrm{In}(\mathbf{1 c})$ also exhibited high reactivity in crosscoupling reactions with acid chlorides (Scheme 3). For example, the reactions of $\mathrm{Me}_{3} \mathrm{In}(\mathbf{1 b})$ with aroyl chlorides bearing various substituents, regardless of their electronic properties and substitution positions, produced the corresponding substituted acetophenones $3 \mathbf{n}-3 \mathbf{r}$ in $86-95 \%$ yields. The reactions of bulky 1naphthoyl chloride and thiophene-2-carbonyl chloride with $\mathrm{Me}_{3}$ In (1b) also proceeded smoothly to furnish the desired coupling products $3 \mathbf{s}$ and $3 \mathbf{t}$ in high yields. In addition, a variety of butyl aryl ketones $3 \mathbf{u}-\mathbf{3 z}$ could be obtained in high yields by the cross-coupling of $n$ - $\mathrm{Bu}_{3} \mathrm{In}(\mathbf{1 c})$ with various aroyl chlorides under the optimized conditions. In all these reactions, the tertiary alcohol resulting from double addition was not detected due to the high chemoselectivity of triorganoindiums. The present method provides a quite general and practical route for the synthesis of a variety of biaryl ketones, substituted acetophenones and butyl aryl ketones. A range of electron-donating and electron-withdrawing groups such as methyl, methoxy, chloro, fluoro, nitro, and cyano on aroyl chlorides were well tolerated.

Encouraged by the above results, the heterogeneous crosscoupling reactions of various trialkynylindiums $\mathbf{1 d - 1 i}$ with a range of acid chlorides were then examined under optimized reaction conditions and the results are listed in Table 4 . The

Table 4 Synthesis of $\alpha, \beta$-acetylenic ketones via heterogeneous palladium(0)-catalyzed cross-coupling of acid chlorides with trialkynylindiums ${ }^{a, b}$

$$
\begin{aligned}
& (\mathrm{R}=)_{3} \ln (0.37 \text { equiv })+\mathrm{Cl}_{2} \frac{\begin{array}{c}
\text { MCM-41-N,N-Pd(0) } \\
(1 \mathrm{~mol} \%)
\end{array}}{\mathrm{THF}, \text { reflux }} \\
& \text { 1d: } \mathrm{R}=\mathrm{Ph} ; 1 \mathrm{e}: \mathrm{R}=p \text {-tolyl; 1f: } \mathrm{R}=n-\mathrm{Bu} \\
& \text { 1g: } \mathrm{R}=n-\mathrm{C}_{6} \mathrm{H}_{13} ; 1 \mathbf{h}: \mathrm{R}=\mathrm{MeOCH}_{2} ; 1 \mathrm{i}: \mathrm{R}=\mathrm{Me}_{3} \mathrm{Si}
\end{aligned}
$$

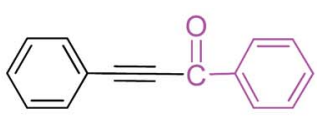

4a, $92 \%$

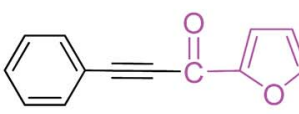

$4 e, 82 \%$

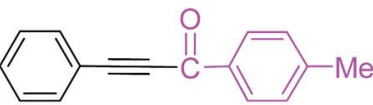

4b, $89 \%$

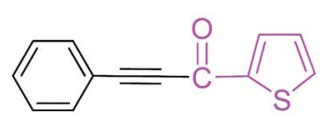

4f, $88 \%$

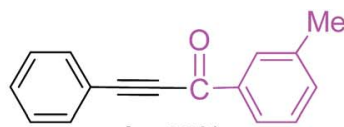

4c, $90 \%$

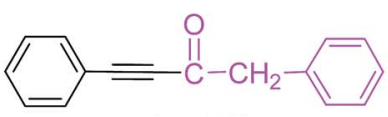

4g, $90 \%$

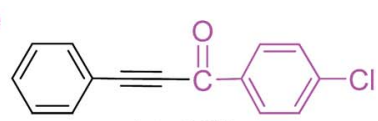

4d, $91 \%$<smiles>CC(=CC#CC(=O)c1ccc(CC#CC(=O)c2ccc([N+](=O)[O-])cc2)cc1)CCc1ccc(C(=O)C#Cc2ccc(COc3ccc(C(=O)C#Cc4ccc(C)cc4)cc3)cc2)cc1</smiles>

$4 \mathrm{i}, 89 \%$

4j, $86 \% \mathrm{MeO}$

4k, $93 \%$

4I, $90 \%$

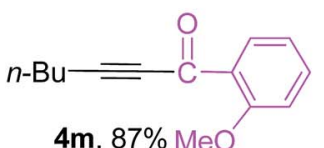<smiles>CCCCC#CC(=O)c1ccco1</smiles>

4n, $84 \%$

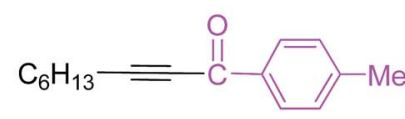

4o, $91 \%$<smiles>Cc1cccc(C(=O)C#CCc2ccccc2)c1</smiles>

4p, $93 \%$<smiles>COc1ccc(C(=O)C#CCc2ccccc2)cc1</smiles>

4q, $89 \%$<smiles>O=C(C#CCc1ccccc1)c1ccco1</smiles>

$4 r, 86 \%$

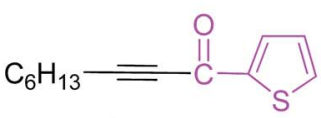

4s, $83 \%$<smiles>COCC#CC(=O)c1ccccc1</smiles>

4t, $87 \%$<smiles>COCC#CC(=O)c1ccc(C)cc1</smiles>
$4 u, 85 \%$ $4 \mathbf{v}, 94 \%$<smiles>C[SiH2]C#CC(=O)c1ccc([Si])cc1</smiles>

4w, $90 \%$

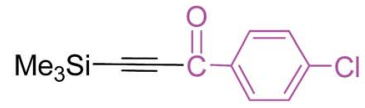

$4 x, 92 \%$

${ }^{a}$ All reactions were performed using $1.0 \mathrm{mmol}$ of acid chloride, $0.37 \mathrm{mmol}$ of $(\mathrm{RC} \equiv \mathrm{C})_{3} \mathrm{In}, 1 \mathrm{~mol} \%$ of $\mathrm{MCM}-41-N, N-\mathrm{Pd}(0)$ in $5.0 \mathrm{~mL}$ of $\mathrm{THF}$ at $68{ }^{\circ} \mathrm{C}$ under $\mathrm{Ar}$ for $2 \mathrm{~h} .{ }^{b}$ Isolated yield based on acid chloride used. 
coupling reactions of tri(phenylethynyl)indium (1d) with a range of electron-neutral, electron-rich and electron-deficient aroyl chlorides proceeded smoothly in THF at $68^{\circ} \mathrm{C}$ to afford the corresponding $\alpha, \beta$-acetylenic ketones $\mathbf{4 a - 4 d}$ in $89-92 \%$ yields. Heteroatoms turned out to be compatible with the employed reaction conditions. The reactions of heteroaroyl chlorides such as furan-2-carbonyl chloride and thiophene-2-carbonyl chloride with 1d produced the expected coupling products $\mathbf{4 e}$ and $\mathbf{4 f}$ in good yields. Besides aroyl and heteroaroyl chlorides, an aliphatic phenylacetyl chloride was also good coupling partner and gave the desired 1,4-diphenylbut-3-yn-2-one $4 \mathrm{~g}$ in $90 \%$ yield. The coupling reaction worked equally well with tri $(p$-tolylethynyl)indium (1e), providing the desired coupling products $\mathbf{4 h}-\mathbf{4 j}$ in $86-91 \%$ yields. In addition to aromatic trialkynylindiums $\mathbf{1 d}$ and $\mathbf{1 e}$, three aliphatic trialkynylindiums $\mathbf{1 f}, \mathbf{1 g}$ and $\mathbf{1 h}$ also showed high reactivity in the cross-couplings with acid chlorides. The reactions of trialkynylindiums $\mathbf{1 f}-\mathbf{1} \mathbf{h}$ with a wide range of electron-neutral, electron-rich and electron-deficient aroyl chlorides or heteroaroyl chlorides proceeded effectively under the optimized reaction conditions to afford the corre-

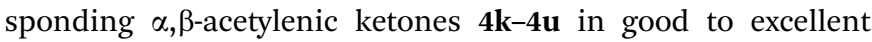
yields. Interestingly, a trimethylsilyl-functionalized trialkynylindium reagent $\mathbf{1 i}$ also underwent the cross-coupling with various aroyl chlorides smoothly to afford the desired trimethylsilyl-functionalized alkynyl ketones $\mathbf{4 v - 4 x}$ in excellent yields. The developed methodology provides a quite general and practical route for the preparation of $\alpha, \beta$-acetylenic ketones having various functionalities.

To verify whether the observed catalysis was due to the heterogeneous MCM-41- $N, N-\operatorname{Pd}(0)$ complex or to a leached palladium species in solution, we performed the hot filtration test. ${ }^{25}$ We focused on the coupling reaction of $\mathrm{Ph}_{3} \mathrm{In}$ with benzoyl chloride. We filtered off the MCM- $41-N, N-\operatorname{Pd}(0)$ complex after $0.5 \mathrm{~h}$ of reaction time and allowed the filtrate to react further. The catalyst filtration was performed at the reaction temperature $\left(68{ }^{\circ} \mathrm{C}\right)$ in order to avoid possible recoordination or precipitation of soluble palladium upon cooling. We found that, after this hot filtration, no further reaction was observed. We also determined the palladium content in the filtrate by ICP analysis, and only $0.3 \mathrm{ppm}$ of palladium was found in the clear solution. These results rule out any contribution to the observed catalysis from a homogeneous palladium species indicating that the catalyst was stable during the reaction and the observed catalysis was intrinsically heterogeneous.

A plausible mechanism for this heterogeneous palladium(0)catalyzed cross-coupling reaction of triorganoindiums with acid chlorides is illustrated in Scheme 4. First, oxidative addition of $\mathrm{R}^{1} \mathrm{COCl}$ (2) to the MCM-41- $N, N-\mathrm{Pd}(0)$ complex provides an MCM-41-bound acylpalladium(II) complex (A), which should be the rate-limiting step. ${ }^{10 a}$ Subsequent transmetalation between intermediate $\mathbf{A}$ and triorganoindium reagent (1) produces intermediate $\mathbf{B}$ and $\mathrm{R}_{2} \mathrm{InCl}$, which can re-enter in a new catalytic cycle and effectively transfer its organic groups. Finally, reductive elimination of intermediate $\mathbf{B}$ affords the desired ketone ( 3 or 4) and regenerates the MCM- $41-N, N-\operatorname{Pd}(0)$ complex to complete the catalytic cycle.

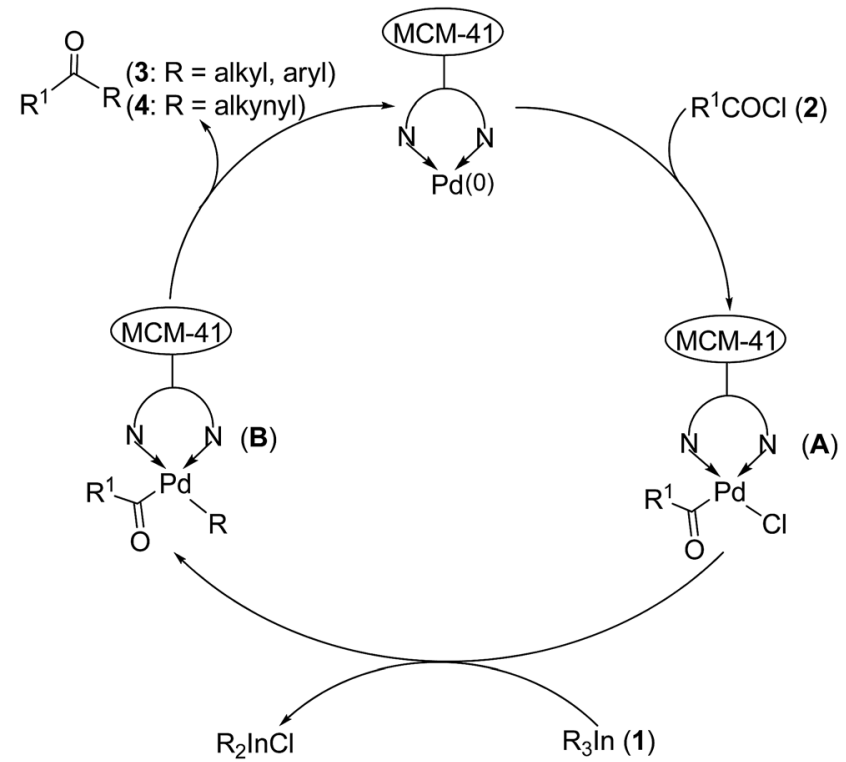

Scheme 4 Proposed catalytic cycle.

For the practical application of a heterogeneous catalyst system its stability and reusability are important factors. The MCM-41- $N, N-\operatorname{Pd}(0)$ complex could be easily separated and recovered by a simple filtration of the reaction solution. We next investigated the recyclability of the catalyst by using the crosscoupling reaction of benzoyl chloride with $\left(\mathrm{Me}_{3} \mathrm{SiC} \equiv \mathrm{C}\right)_{3} \mathrm{In}$ (1i). After carrying out the reaction, the catalyst was recovered by simple filtration and washed with DMF and diethyl ether. After being air-dried, it can be reused directly without further purification. The recovered palladium catalyst was used in the next run, and almost the same yield of $\mathbf{4 v}$ was obtained for ten consecutive cycles (Fig. 1). In addition, palladium leaching in the heterogeneous catalyst was also determined by ICP-AES analysis on the recovered catalyst after ten consecutive runs, which revealing almost the same palladium content as the fresh one. The high catalytic performance and excellent recyclability of the MCM-41- $N, N-\operatorname{Pd}(0)$ catalyst may relate to the efficient site isolation, to the optimal dispersion of the active sites on the inner channel walls and to the relatively strong interaction

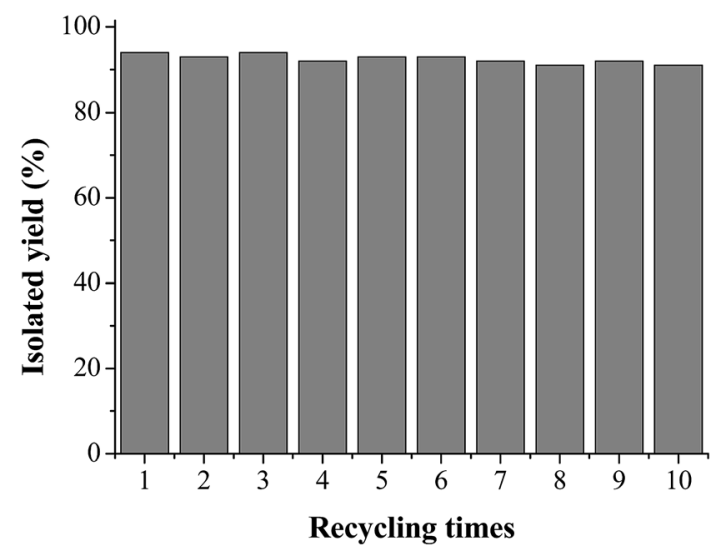

Fig. 1 Recycle of the MCM-41-N,N-Pd(0) catalyst. 
between bidentate Schiff base ligand and the palladium centre anchored on the MCM-41. The result is important from the standpoint of green and sustainable chemistry.

\section{Conclusions}

In summary, we have successfully developed a novel, atomefficient, practical and environmentally friendly method for the synthesis of aryl ketones and $\alpha, \beta$-acetylenic ketones through the cross-coupling of triorganoindiums with acid chlorides by using an MCM-41-immobilized palladium(0)-Schiff base complex $[\mathrm{MCM}-41-N, N-\operatorname{Pd}(0)]$ as catalyst. This heterogeneous phosphine-free palladium( 0 ) catalyst could be easily prepared by a simple procedure from commercially readily available reagents and exhibited the same catalytic activity as $\mathrm{Pd}\left(\mathrm{PPh}_{3}\right)_{4}$. The reactions generated a variety of valuable aryl ketones and $\alpha, \beta$-acetylenic ketones in good to excellent yields and were applicable to various triorganoindiums and a wide range of acid chlorides. In addition, this methodology offers the competitiveness of recyclability of the palladium catalyst without significant loss of activity, and the palladium catalyst can be easily recovered by a simple filtration of the reaction solution and reused at least 10 cycles, thus making this procedure economically and environmentally more acceptable.

\section{Experimental}

All chemicals were reagent grade and used as purchased. All solvents were dried and distilled before use. The MCM-41- $N, N$ $\mathrm{Pd}(\mathrm{OAc})_{2}$ catalyst was prepared according to our previous procedure, ${ }^{21}$ the palladium content was determined to be $0.42 \mathrm{mmol} \mathrm{g}^{-1}$. The products were purified by flash chromatography on silica gel. Mixture of EtOAc and hexane was generally used as eluent. All coupling products were characterized by comparison of their spectra and physical data with authentic samples. ${ }^{1} \mathrm{H}$ NMR spectra were recorded on a Bruker Avance $400 \mathrm{MHz}$ spectrometer with TMS as an internal standard in $\mathrm{CDCl}_{3}$ as solvent. ${ }^{13} \mathrm{C} \mathrm{NMR}$ spectra $(100 \mathrm{MHz})$ were recorded on a Bruker Avance $400 \mathrm{MHz}$ spectrometer in $\mathrm{CDCl}_{3}$ as solvent. HRMS spectra were recorded on a Q-Tof spectrometer with micromass MS software using electrospray ionization (ESI). Melting points are uncorrected. X-ray photoelectron spectra was recorded on XSAM 800 (Kratos). Palladium content was determined with inductively coupled plasma atom emission Atomscan16 (ICP-AES, TJA Corporation).

\section{Preparation of the MCM-41- $N, N-P d(0)$ complex}

A mixture of $\mathrm{MCM}-41-N, N-\mathrm{Pd}(\mathrm{OAc})_{2}(2.5 \mathrm{~g})$ and hydrazine hydrate $(1.5 \mathrm{~g})$ in $\mathrm{EtOH}(30 \mathrm{~mL})$ was stirred at $30{ }^{\circ} \mathrm{C}$ for $3 \mathrm{~h}$ under Ar. The resulting product was filtered, washed with $\mathrm{EtOH}(3 \times$ $20 \mathrm{~mL})$ and $\mathrm{Et}_{2} \mathrm{O}(2 \times 20 \mathrm{~mL})$ and dried under vacuum at $60{ }^{\circ} \mathrm{C}$ for $3 \mathrm{~h}$ to afford $2.38 \mathrm{~g}$ of the MCM-41-N,N-Pd(0) complex as a gray powder. The nitrogen content was found to be $2.24 \mathrm{mmol}$ $\mathrm{g}^{-1}$ by elemental analysis. The palladium content was determined to be $0.43 \mathrm{mmol}^{-1}$ by ICP-AES.

\section{General procedure for preparation of triorganoindium} reagents

A $25 \mathrm{~mL}$ round-bottomed flask containing a stirrer bar was charged with $\mathrm{InCl}_{3}(0.37 \mathrm{mmol})$ and dried under vacuum with a heat gun. The flask was cooled, a positive argon pressure was established and anhydrous THF $(2 \mathrm{~mL})$ was added. The resulting solution was cooled to $-78{ }^{\circ} \mathrm{C}$ and a solution of $\mathrm{RLi}$ or RMgBr (1.1 mmol, 1.0-2.5 $\mathrm{M}$ in hexane, THF, or $\mathrm{Et}_{2} \mathrm{O}$ ) was slowly added (15-30 $\mathrm{min})$. The reaction mixture was stirred for $30 \mathrm{~min}$, the cooling bath was removed, and the mixture was warmed to room temperature over $30 \mathrm{~min}$.

\section{General procedure for the heterogeneous palladium(0)- catalyzed cross-coupling of acid chlorides with triorganoindiums}

A solution of $\mathrm{R}_{3} \mathrm{In}(0.37 \mathrm{mmol}, \mathrm{ca} .0 .18 \mathrm{M}$ in dry THF) was added to a mixture of MCM-41-N,N-Pd(0) (24 mg, $1 \mathrm{~mol} \%$ ) and acid chloride $(1 \mathrm{mmol})$ in dry THF $(3 \mathrm{~mL})$ under Ar. The resulting mixture was refluxed under Ar until the starting material had been consumed (TLC). After being cooled to room temperature, the mixture was diluted with $\mathrm{Et}_{2} \mathrm{O}(30 \mathrm{~mL})$ and filtered. The palladium catalyst was washed with DMF $(2 \times 5 \mathrm{~mL}), \mathrm{Et}_{2} \mathrm{O}(2 \times$ $5 \mathrm{~mL}$ ) and reused in the next run. The filtrate was washed with sat. aq $\mathrm{NaHCO}_{3}(5 \mathrm{~mL})$, water $(3 \times 10 \mathrm{~mL})$ and dried over $\mathrm{MgSO}_{4}$, filtered, and concentrated under vacuum. The residue was purified by flash chromatography on silica gel (EtOAc : hexane $=1: 25$ ) to give the desired cross-coupling product.

\section{Conflicts of interest}

There are no conflicts of interest to declare.

\section{Acknowledgements}

We thank the National Natural Science Foundation of China (No. 21462021) and Key Laboratory of Functional Small Organic Molecule, Ministry of Education (No. KLFS-KF-201409) for financial support.

\section{References}

1 (a) N. De Kimpe, M. Keppens and G. Froncg, J. Chem. Soc., Chem. Commun., 1996, 635-636; (b) R. K. Dieter, Tetrahedron, 1999, 55, 4177-4236; (c) X.-J. Wang, L. Zhang, X. Sun, Y. Xu, D. Krishnamurthy and C. H. Senanayake, Org. Lett., 2005, 7, 5593-5595; (d) B. Hatano, J. I. Kadokawa and H. Tagaya, Tetrahedron Lett., 2002, 43, 5859-5861; (e) F. W. Patureau, T. Besset, N. Kuhl and F. Glorius, J. Am. Chem. Soc., 2011, 133, 2154-2156; (f) L. Zheng, J. Ju, Y. Bin and R. Hua, J. Org. Chem., 2012, 77, 5794-5800.

2 (a) V. I. Dodero, L. C. Koll, M. B. Faraoni, T. N. Mitchell and J. C. Podesta, J. Org. Chem., 2003, 68, 10087-10091; (b) B. G. Vong, S. H. Kim, S. Abraham and E. A. Theodorakis, Angew. Chem., Int. Ed., 2004, 43, 3947-3951; (c) B. M. Trost and Z. T. Ball, J. Am. Chem. Soc., 2004, 126, 13942-13944; 
(d) B. M. Trost and T. Schmidt, J. Am. Chem. Soc., 1988, 110, 2301-2303; (e) A. V. Kel'in, A. W. Sromek and V. Gevorgyan, J. Am. Chem. Soc., 2001, 123, 2074-2075; $(f)$ A. V. Kel'in and V. Gevorgyan, J. Org. Chem., 2002, 67, 95-98; $(g)$ B. M. Trost and C.-I. Huang, J. Am. Chem. Soc., 2015, 137, 15940-15946; (h) T. Wang, X. Duan, H. Zhao, S. Zhai, C. Tao, H. Wang, Y. Li, B. Cheng and H. Zhai, Org. Lett., 2017, 19, 1650-1653. 3 (a) A. Furstner, D. Voigtlander, W. Schrader, D. Giebel and M. T. Reetz, Org. Lett., 2001, 3, 417-420; (b) C. E. Song, W. H. Shim, E. J. Roh and J. H. Choi, Chem. Commun., 2000, 1695-1696; (c) J. Ross and J. Xiao, Green Chem., 2002, 4, 129-133; (d) S. Gmouh, H. Yang and M. Vaultier, Org. Lett., 2003, 5, 2219-2222; (e) E. Fillion, D. Fishlock, A. Wilsily and J. M. Goll, J. Org. Chem., 2005, 70, 1316-1327.

4 (a) R. B. Davis and D. H. Scheiber, J. Am. Chem. Soc., 1956, 78, 1675-1678; (b) M. W. Logue and G. L. Moore, J. Org. Chem., 1975, 40, 131-132; (c) U. Schmit and M. Schwochau, Chem. Ber., 1964, 97, 1649-1655; (d) L. I. Vereshchagin, O. G. Yashina and T. V. Zarva, Zh. Org. Khim., 1966, 2, 1895-1901; (e) D. R. M. Walton and F. Waugh, J. Organomet. Chem., 1972, 37, 45-56; (f) M. W. Logue and K. Teng, J. Org. Chem., 1982, 47, 2549-2553.

5 (a) D. A. Alonso, C. Najera and M. C. Pacheco, J. Org. Chem., 2004, 69, 1615-1619; (b) J. Yin, X.-J. Wang, Y. Liang, X. Wu, B. Chen and Y. Ma, Synthesis, 2004, 331-336; (c) L. Chen and C.-J. Li, Org. Lett., 2004, 6, 3151-3154; (d) R. J. Cox, D. J. Ritson, T. A. Dane, J. Berge, J. P. H. Charmant and A. Kantacha, Chem. Commun., 2005, 1037-1038; (e) S. S. Palimkar, R. J. Lahoti and K. V. Srinivasan, Green Chem., 2007, 9, 146-152; $(f)$ H.-L. Liu, H.-F. Jiang, M. Zhang, W.-J. Yao, Q.-H. Zhu and Z. Tang, Tetrahedron Lett., 2008, 49, 3805-3808; $(g)$ Y. Nishihara, E. Inoue, Y. Okada and K. Takagi, Synlett, 2008, 3041-3045.

6 B. M. Trost, Angew. Chem., Int. Ed., 1995, 34, 259-281.

7 (a) P. T. Anastas and J. C. Warner, Green Chemistry, Oxford University Press, Oxford, 1998, pp. 29-55; (b) P. T. Anastas and M. M. Kirchhoff, Acc. Chem. Res., 2002, 35, 686-694.

8 I. J. Worrall and J. D. Smith, in Organometallic Compounds of Aluminum, Gallium, Indium and Thallium, ed. A. McKillop, J. D. Smith and I. J. Worrall, Chapman and Hall, London, U.K., 1985, p. 137.

9 (a) R. Jana, T. P. Pathak and M. S. Sigman, Chem. Rev., 2011, 111, 1417-1492; (b) Z.-L. Shen, S.-Y. Wang, Y.-K. Chok, Y.-H. Xu and T.-P. Loh, Chem. Rev., 2013, 113, 271-401.

10 For selected examples, see: (a) L. Perez, J. Perez Sestelo and L. A. Sarandeses, J. Am. Chem. Soc., 2001, 123, 4155-4160; (b) M. A. Pena, J. Perez Sestelo and L. A. Sarandeses, Synthesis, 2005, 485-492; (c) M. A. Pena, J. Perez Sestelo and L. A. Sarandeses, J. Org. Chem., 2007, 72, 1271-1275; (d) S. Bernhardt, Z.-L. Shen and P. Knochel, Chem.-Eur. J., 2013, 19, 828-833; (e) C. Perez-Caaveiro, J. Perez Sestelo and L. A. Sarandeses, J. Org. Chem., 2014, 79, 9586-9593; (f) A. Mosquera, M. I. Fernandez, M. Canle Lopez, J. Perez Sestelo and L. A. Sarandeses, Chem.-Eur. J., 2014, 20, 14524-14530; $(g)$ S. Thapa, S. K. Gurung, D. A. Dickie and R. Giri, Angew. Chem., Int. Ed., 2014, 53, 11620-11624.
11 (a) P. H. Lee, S. W. Lee and K. Lee, Org. Lett., 2003, 5, 11031106; (b) M. A. Pena, J. Perez Sestelo and L. A. Sarandeses, Synthesis, 2003, 780-784; (c) S. K. Lee, K. Lee, D. Seomoon, S. Kim, H. Kim, H. Kim, E. Shim, M. Lee, S. Lee, M. Kim and P. H. Lee, J. Org. Chem., 2004, 69, 4852-4855.

12 (a) M. Poliakoff, J. M. Fitzpatrick, T. R. Farren and P. T. Anastas, Science, 2002, 297, 807-810; (b) D. J. ColeHamilton, Science, 2003, 299, 1702-1706.

13 (a) N. E. Leadbeater and M. Marco, Chem. Rev., 2002, 102, 3217-3274; (b) L. Yin and J. Liebscher, Chem. Rev., 2007, 107, 133-173; (c) J. Liu and P. H. Toy, Chem. Rev., 2009, 109, 815-838; (d) A. Molnar, Chem. Rev., 2011, 111, 22512320.

14 (a) C. T. Kresge, M. E. Leonowicz, W. J. Roth, J. C. Vartuli and J. S. Beck, Nature, 1992, 359, 710-712; (b) T. Maschmeyer, F. Rey, G. Sankar and J. M. Thomas, Nature, 1995, 378, 159-162; (c) W. Zhou, J. M. Thomas, D. S. Shephard, B. F. G. Johnson, D. Ozkaya, T. Maschmeyer, R. G. Bell and Q. Ge, Science, 1998, 280, 705-708; (d) A. Taguchi and F. Schuth, Microporous Mesoporous Mater., 2005, 77, 1-45; (e) R. M. Martin-Aranda and J. Cejka, Top. Catal., 2010, 53, 141-153.

15 J. S. Beck, J. C. Vartuli, W. J. Roth, M. E. Leonowicz, C. T. Kresge, K. D. Schmitt, C. T.-W. Chu, D. H. Olson, E. W. Sheppard, S. B. Mccullen, J. B. Higgins and J. L. Schlenker, J. Am. Chem. Soc., 1992, 114, 10834-10843.

16 For selected examples, see: (a) P. C. Mehnert, D. W. Weaver and J. Y. Ying, J. Am. Chem. Soc., 1998, 120, 12289-12296; (b) K. Mukhopadhyay, B. R. Sarkar and R. V. Chaudhari, J. Am. Chem. Soc., 2002, 124, 9692-9693; (c) J. Y. Ying, C. P. Mehnert and M. S. Wong, Angew. Chem., Int. Ed., 1999, 38, 56-77; (d) M. Cai, G. Zheng and G. Ding, Green Chem., 2009, 11, 1687-1693; (e) M. Cai, J. Peng, W. Hao and G. Ding, Green Chem., 2011, 13, 190-196; ( $f)$ W. Hao, H. Liu, L. Yin and M. Cai, J. Org. Chem., 2016, 81, 42444251; $(g)$ F. Havasi, A. Ghorbani-Choghamarani and F. Nikpour, New J. Chem., 2015, 39, 6504-6512.

17 (a) S.-G. Shyu, S.-W. Cheng and D.-L. Tzou, Chem. Commun., 1999, 2337-2338; (b) Y. Yang and R. M. Rioux, Chem. Commun., 2011, 47, 6557-6559.

18 (a) C. D. Nunes, A. A. Valente, M. Pillinger, A. C. Fernandes, C. C. Romao, J. Rocha and I. S. Goncalves, J. Mater. Chem., 2002, 12, 1735-1742; (b) M. Jia, A. Seifert and W. R. Thiel, Chem. Mater., 2003, 15, 2174-2180.

19 (a) A. Corma, E. Gutierrez-Puebla, M. Iglesias, A. Monge, S. Perez-Ferreras and F. Sanchez, Adv. Synth. Catal., 2006, 348, 1899-1907; (b) A. Corma, C. Gonzalez-Arellano, M. Iglesias and F. Sanchez, Angew. Chem., Int. Ed., 2007, 46, 7820-7822; (c) G. Villaverde, A. Corma, M. Iglesias and F. Sanchez, ACS Catal., 2012, 2, 399-406; (d) W. Yang, R. Zhang, F. Yi and M. Cai, J. Org. Chem., 2017, 82, 52045211.

20 (a) R. Xiao, H. Zhao and M. Cai, Tetrahedron, 2013, 69, 54445450; (b) H. Zhao, W. He, R. Yao and M. Cai, Adv. Synth. Catal., 2014, 356, 3092-3098; (c) M. Cai, R. Yao, L. Chen and H. Zhao, J. Mol. Catal. A: Chem., 2014, 395, 349-354; (d) H. Zhao, Y. Jiang, Q. Chen and M. Cai, New J. Chem., 
2015, 39, 2106-2111; (e) H. Zhao, W. He, L. Wei and M. Cai, Catal. Sci. Technol., 2016, 6, 1488-1495.

21 C. Xu, L. Yin, B. Huang, H. Liu and M. Cai, Tetrahedron, 2016, 72, 2065-2071.

22 L. Yu, Y. Huang, Z. Wei, Y. Ding, C. Su and Q. Xu, J. Org. Chem., 2015, 80, 8677-8683.
23 M. Cai, Q. Xu and Y. Huang, J. Mol. Catal. A: Chem., 2007, 271, 93-97.

24 H. Zhao, L. Yin and M. Cai, Eur. J. Org. Chem., 2013, 13371345.

25 H. E. B. Lempers and R. A. Sheldon, J. Catal., 1998, 175, 6269. 